\title{
Sudden bilateral hearing loss in gastric cancer as the only symptom of disease
}

This article was published in the following Dove Press journal:

OncoTargets and Therapy

2 June 2015

Number of times this article has been viewed

\author{
Zoran Rakusic' \\ Ana Misir Krpan' \\ Darija Stupin Polancec ${ }^{2}$ \\ Antonia Jakovcevic ${ }^{3}$ \\ Vesna Bisof' \\ 'Department of Oncology, University \\ Hospital Center Zagreb, ${ }^{2}$ Fidelta \\ Ltd for Research and Development, \\ ${ }^{3}$ Department of Pathology, University \\ Hospital Center Zagreb, Zagreb, \\ Croatia
}

\begin{abstract}
This paper reports a case of sudden bilateral deafness as the first symptom of gastric cancer, an extremely rare and atypical clinical situation. Because common signs of stomach cancer were absent, the patient was first evaluated in the Department of Otolaryngology, University Hospital Center, Zagreb. Only after expanded diagnostic evaluation and rapid progression of the disease in such a case is a malignant tumor suspected. Treatment is mostly ineffective. The unusual presentation of the disease and the rapid course may indicate a hereditary predisposition. Inactivation of tumor suppressor gene DFNA5 was found in $50 \%$ of gastric cancers, but of a non-metastasized phenotype. Inactivated DFNA5, otherwise described in hereditary bilateral deafness, perhaps favors the development of deafness in patients with gastric cancer. Our patient had a positive multiple viral antibody titer in serum, inactivated DFNA5 in both gastric cancer tissues and cerebellar metastases, and a metastatic form of the disease. If sudden deafness occurs in elderly patients, the possibility of malignant tumor should be taken into consideration. The link between gastric cancer and the DFNA5 gene is unclear and requires further research.
\end{abstract}

Keywords: deafness, gastric cancer, DFNA5 gene, meningeal carcinomatosis

\section{Background}

Meningeal carcinomatosis (MC) is an involvement of the pia and arachnoid membranes by cancer cells that metastasize from solid tumors. It is a rare event in solid tumors, with an incidence of $5 \%-8 \%$, and is mostly diagnosed in lung, breast, and gastric cancers. ${ }^{1}$ The incidence of $\mathrm{MC}$ in patients with gastric cancer has been reported as $0.16 \%-0.69 \%$. $^{2,3}$ In patients with gastric cancer and MC, only $10 \%$ have vestibulocochlear nerve involvement, unilaterally or bilaterally, with extremely rare occurrence of sudden deafness. ${ }^{4}$ Signs and symptoms represent involvement of cranial nerves, usually III, V, and VII. Diagnosis is made by neurological examination, magnetic resonance imaging (MRI), and cerebrospinal fluid (CSF) analysis. MRI shows diffuse leptomeningeal enhancement and CSF malignant cells with increased protein levels and decreased glucose levels. CSF could be negative in first lumbar puncture, but repeating the procedure reveals cancer cells in most cases.

Treatment options are very limited. The best results are obtained with a combination of whole brain radiotherapy, intrathecal chemotherapy, and systemic therapy in patients with good Karnofsky Performance Status scores. ${ }^{5,6}$ Despite treatment, the course of disease usually leads to rapid progression and death in several months.

\section{Case presentation}

A 60-year-old woman presented with mild dizziness and occasional headaches. Otherwise she was healthy, without known history of malignant disease, and in excellent general condition. Standard laboratory tests were normal as well as neurological 
examination and initial brain MRI. She reported impaired hearing and an audiogram indicated bilateral sensorineural hearing impairment. Corticosteroids were administered by an otolaryngologist, with no improvement.

A lumbar puncture was done and cytological examination of the CSF found adenocarcinoma cells. Deafness was clinically obvious and was confirmed on control audiogram performed 3 weeks after the initial audiology examination. Extended diagnostic evaluation detected positive immunoglobulin G antibodies to Epstein-Barr virus (EBV), cytomegalovirus, varicella zoster virus, and herpes simplex virus type 2. Control MRI was performed to assess the progression of neurological deficit. MC and two cerebellar secondary lesions were seen and there was bilateral enhancement and striking thickening of both vestibulocochlear nerves (Figure 1), also consistent with MC. A computed tomography scan detected a suspicious primary pancreatic lesion and enlarged retroperitoneal lymph nodes. A tumor marker carcinoembryonic antigen (CEA) was elevated but other laboratory findings were normal.

She was admitted to the Department of Oncology and within the next 2 days a rapid deterioration in general condition and loss of consciousness were recorded. The patient died 6 weeks from the first symptoms of the disease, without a diagnosis or treatment. The autopsy report described poorly

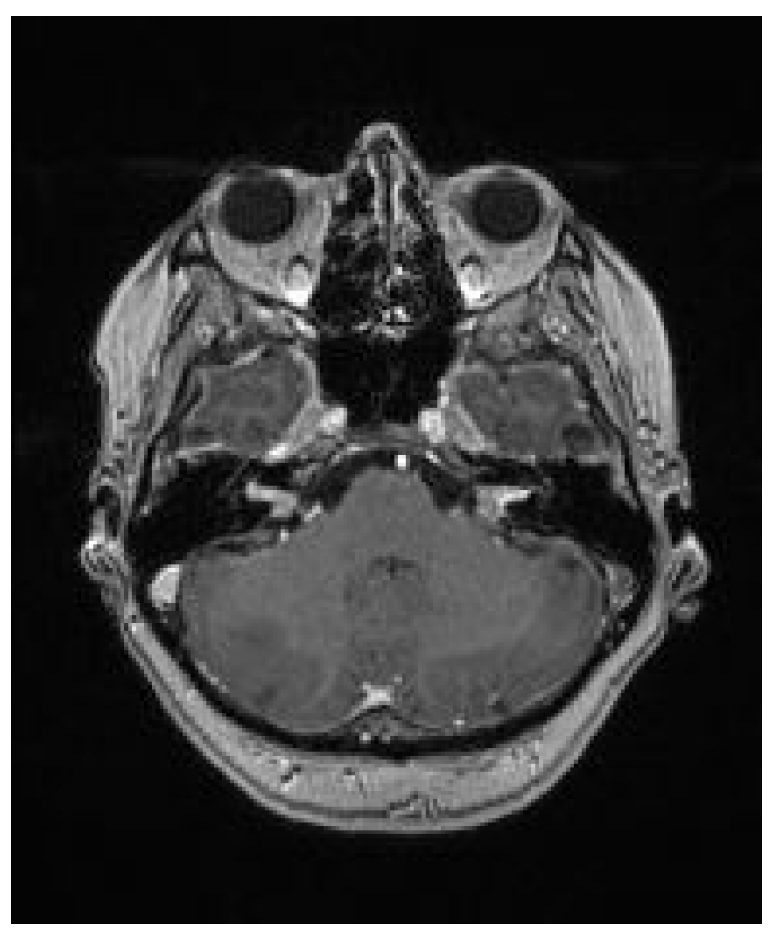

Figure I Brain axial magnetic resonance imaging TI-weighted sequence after gadolinium intravenous administration showing thickening and enhancement of bilateral vestibulocochlear nerves and solitary lesion in right cerebellar hemisphere. differentiated ulcerative gastric cancer (Figure 2), tumor enlarged abdominal lymph nodes, $\mathrm{MC}$, and subcortical cerebellar metastasis. Helicobacter pylori testing was negative. She was not treated because of unclear disease presentation, no histology verification of malignant disease, and extremely rapid deterioration during diagnostic procedures.

\section{Discussion}

$\mathrm{MC}$ is extremely rarely the first sign of malignancy. In gastric cancer, MC occurs in advanced disease. The literature has described only a few cases when stomach cancer has first manifested with bilateral deafness (Table 1). Interestingly, all patients previously described in the literature were men. In four out of six patients, including ours, the diagnosis was set following autopsy. It is not easy to explain the mechanism of such disease presentation, since the symmetrical distribution in the area of both the vestibulocochlear nerves and internal acoustic meatus may not be a consequence of a random sequence of events. It is not known whether an audiological neuropathy or gene mutations in patients with gastric cancer could lead to sudden and fast bilateral deafness.

There are limited published data describing the relationship between the DFNA5 gene and bilateral deafness that is inherited in an autosomal dominant pattern. ${ }^{7}$ In addition, $D F N A 5$, formerly called ICERE-1 (inversely correlated with estrogen receptor expression), is downregulated or its expression is absent in various types of cancer due to DNA methylation of cytosine-phosphate-guanine sites in the promoter region. ${ }^{8-10}$ The relationship between the inactivation of DFNA5 and certain types of cancer, such as breast, stomach, and colon, has been described. DFNA5 mutation is revealed in $50 \%$ of gastric tumors, and was correlated with

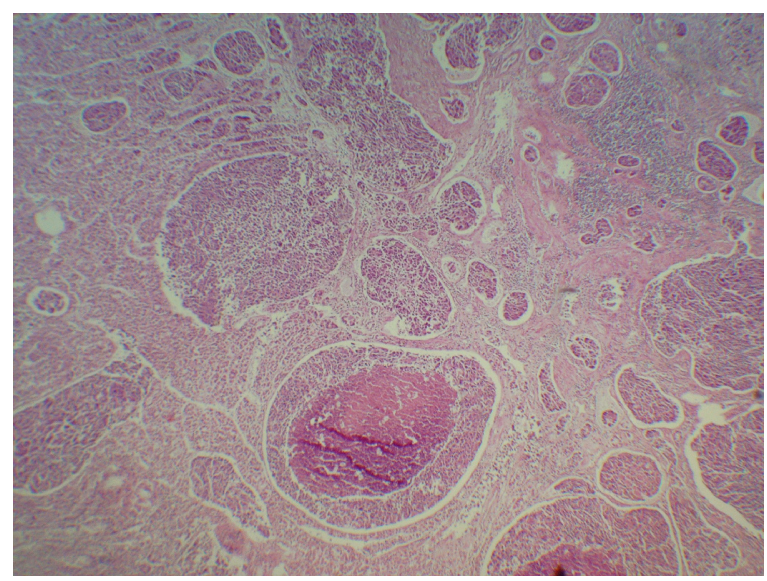

Figure 2 Entire stomach wall infiltrated with solid nests of tumor tissue, with occasional central necrosis. Tumor is adenocarcinoma grade III. Notes: Hematoxylin and eosin stain; $\times 200$ magnification. 
Table I Bilateral hearing loss as presenting symptom of gastric cancer

\begin{tabular}{|c|c|c|c|c|c|c|c|c|}
\hline Study & Cases, $\mathbf{n}$ & Sex, M/F & Age, years & Symptom(s) & $\begin{array}{l}\text { Diagnosis } \\
\text { method(s) }\end{array}$ & Metastatic site(s) & Treatment & $\begin{array}{l}\text { Survival, } \\
\text { months }\end{array}$ \\
\hline Ohno et al $2010^{16}$ & 1 & M & 62 & Bilateral HL & $\begin{array}{l}\text { MRI brain, } \\
\text { EGD }\end{array}$ & $\begin{array}{l}\text { Lymph nodes, brain, } \\
\text { spinal meninges }\end{array}$ & $\begin{array}{l}\text { S-I, } \\
\text { paclitaxel RT }\end{array}$ & 3.0 \\
\hline Okamoto et al $2007^{17}$ & 1 & M & 63 & Bilateral HL & MRI, autopsy & Meninges & - & 2.5 \\
\hline Schneider et al $2009^{18}$ & 1 & M & Middle-aged & Bilateral HL & $\begin{array}{l}\text { MRI, EGD, } \\
\text { autopsy }\end{array}$ & $\begin{array}{l}\text { Bone marrow, } \\
\text { pancreatic, meninges }\end{array}$ & - & 3.0 \\
\hline Cserni et al $2007^{19}$ & 1 & M & 62 & $\begin{array}{l}\text { Bilateral HL, } \\
\text { headache, vomiting }\end{array}$ & CSF, autopsy & Widely metastasized & - & 1.0 \\
\hline Miura et al $2006^{20}$ & I & M & 70 & $\begin{array}{l}\text { Dizziness, } \\
\text { headache, } \mathrm{HL}\end{array}$ & CSF, EGD & Meninges & $\begin{array}{l}\text { S-I, MTX } \\
\text { intrathecal }\end{array}$ & 12.0 \\
\hline
\end{tabular}

Abbreviations: CSF, cerebrospinal fluid; EGD, esophagogastroduodenoscopy; HL, hearing loss; M, male; MRI, magnetic resonance imaging; MTX, methotrexate; RT, radiotherapy; S-I, oral fluoropyrimidine.

positivity for Epstein-Barr virus and no metastasis (Akino et al), which was not the case in our patient. There are some data in the literature that describe connection between such methylated phenotype and EBV, but molecular mechanism is not fully understood. ${ }^{10}$ It is a tumor suppressor gene regulating apoptosis, and epigenetic inactivation by hypermethylation promotes the alteration of malignant cells. The DFNA5 gene, responsible for hearing loss and involved in cancer, encodes a novel apoptosis-inducing protein. ${ }^{11}$

Expression of DFNA5 at the mRNA level was studied by quantitative real-time polymerase chain reaction (qRT-PCR) analysis of paraffin-embedded gastric tumor tissue samples of our patient. Total RNA was isolated using RNeasy FFPE kit (Qiagen, Venlo, the Netherlands). Concentration and quality of isolated total RNA were determined on an Agilent Technologies 2100 bioanalyzer. First-strand complementary DNA with random hexamers was synthesized using an Invitrogen SuperScript III FirstStrand synthesis system for qRT-PCR (Thermo Fisher Scientific, Waltham, MA, USA) according to the manufacturer's instructions. Expression of DFNA5 at the mRNA level was analyzed by qRT-PCR on an Applied Biosystems 7300 Real-Time PCR (polymerase chain reaction) system (Thermo Fisher Scientific) using the TaqMan method and glycerin-aldehyde-3-phosphate (GAPDH) as a housekeeping gene. Primers and probes were designed in Primer Express software version 3.0 and used at validated concentrations. The sequences of primers and TaqMan probes used were: for GAPDH, 5'-ACCCACTCCTCCACCTTTGAC-3' (forward), 5'-CATACCAGGAAATGAGCTTGACAA-3' (reverse) and 5'-CTGGCATTGCCCTCAACGACCA-3' (TaqMan probe), and for DFNA5, 5'-CTTGCTGCAAACTCCAGATCA-3' (forward), 5'-AGATCAGATACTCCATCATCAGACAGA-3' (reverse) and 5'-CCACACTGTGCCACTTGCTTCGT-3' (TaqMan probe).
qRT-PCR was performed in a $50 \mu \mathrm{L}$ final volume containing $1 \times$ Applied Biosystems TaqMan PCR Master Mix (Thermo Fisher Scientific), $100 \mathrm{nM}$ GAPDH and DFNA5 primers and probes, and $1 \mu \mathrm{L}$ cDNA. Amplification was performed using the following cycling conditions: 2 minutes at $50^{\circ} \mathrm{C}, 10 \mathrm{~min}$ utes at $95^{\circ} \mathrm{C}$, and 45 two-step cycles of 15 seconds at $95^{\circ} \mathrm{C}$ and 60 seconds at $60^{\circ} \mathrm{C}$. Triplicate RT-PCR analyses were executed for each sample, and the obtained threshold cycle $(\mathrm{Ct})$ values were averaged. Tests revealed expression of GAPDH as endogenous control and no measurable amount of DFNA5, which means that the gene was inactivated, most likely by hypermethylation as reported in other papers. ${ }^{10,12}$ DFNA5 was also absent in the brain metastasis of our patient.

As a control, we tested the stomach tissue samples of healthy people in whom we had detected measurable amounts of DFNA5 and housekeeping gene GAPDH (Table 2). Testing was repeated on two tissue samples of healthy stomach from two different people. A sample of normal human stomach was taken 6 hours post mortem from a 50-year-old patient who died of cardiac arrest. His family gave consent for taking a small part of healthy stomach tissue for PCR analysis. The other biopsy specimen of healthy patient was taken during esophagogastroduodenoscopy. The specimens of healthy stomach tissue samples were fixed in $10 \%$ formalin for 24 hours. After the specimens were dehydrated

Table 2 Threshold cycle values by quantitative real-time polymerase chain reaction

\begin{tabular}{lll}
\hline Sample & C $_{\text {T }}$ values & \\
\cline { 2 - 3 } & GAPDH & DFNA5 \\
\hline GC & $28.02 \pm 0.77$ & ND $(>40)$ \\
BM & $27.36 \pm 0.85$ & ND $(>40)$ \\
HST & $25.65 \pm 1.34$ & $33.56 \pm 2.38$ \\
\hline
\end{tabular}

Abbreviations: $B M$, brain metastasis; $C_{T}$, threshold cycle; GAPDH, glyceraldehyde 3-phosphate dehydrogenase; GC, gastric cancer; HST, healthy stomach tissue; ND, not determined. Values are expressed as averages $\pm S D$ and are derived from three isolations. 
and embedded in paraffin wax, $5 \mu \mathrm{m}$ sections were cut and stained with hematoxylin and eosin for light microscopy to histologically prove normal stomach tissue. Triplicate realtime PCR analyses were executed.

Akino et al reported that gastric cancers with DFNA5 inactivation did not show distant metastases which are contrary to our results. ${ }^{10}$ Specifically, in our patient, gastric primary with DFNA5 inactivation had metastasized to the lymph nodes, brain, and meninges. Such a rapid course of disease is not a characteristic of gastric cancer and there were no typical symptoms, such as weight loss, epigastric discomfort, pain, or fatigue, which represents an additional differential diagnostic problem. MRI is the method of choice in the diagnosis of MC. In our case, MRI showed bilaterally significantly thickened nerve VIII. Unilateral pathological lesion in the area of the internal acoustic meatus includes more often primary, benign tumors such as vestibular schwannomas and meningiomas, while neurofibromatosis type II should be considered when there are bilateral positive findings. In these benign tumors, the course of disease is slow and the sudden emergence of symptoms, sensorineural hearing loss, and facial nerve paresis should draw attention to possible metastases. Patients with a known primary tumor or multiple secondary parenchymal lesions are easily diagnosed with less delay. Of the few cases described in the literature, only patients with intrathecal chemotherapy lived significantly longer than the others, which makes this the only effective way to treat these patients if diagnosis is set on time; however, no evidence is currently available from clinical trials. ${ }^{4,13,14}$

The relationship between the DFNA5 gene, gastric cancer, and deafness is still unclear, but unusual clinical presentation suggests a possible connection. A possible explanation is that some external factor - such as EBV - that causes DFNA5 gene mutation in patients with gastric cancer results in an aggressive clinical disease course. Hereditary predisposition or mutations in the same gene, in addition to the MC present, lead to a rapid apoptosis of terminally differentiated cells such as cochlear hair cells, and bilateral deafness becomes a dominant clinical symptom of the disease. ${ }^{15}$

Patients with sudden bilateral deafness usually come first to the ear, nose, and throat specialist, and an oncologist is consulted only at the time of symptoms worsening. Due to extremely rapid disease progression, treatment usually cannot be applied, or is late and inefficient, leading to short survival (on average, less than 2 months after the first presentation of the disease). ${ }^{4}$

\section{Conclusion}

Sudden bilateral hearing loss as the only manifestation of gastric cancer is extremely rare. In such cases, the ear, nose, and throat specialist, who will usually be the first to see the patient, should consider a distal malignancy when no obvious cause of symptoms is found and should focus on diagnostic testing in order to begin treatment with intrathecal chemotherapy and radiation therapy as soon as possible. The role of DFNA5 as a new and possible target in gastric cancer requires further scientific research.

\section{Disclosure}

The authors report no conflicts of interest in this work.

\section{References}

1. Martins SJ, Azevedo CR, Chinen LT, Cruz MR, Peterlevitz MA, Gimenes DL. Meningeal carcinomatosis in solid tumors. Arq Neuropsiquiatr. 2011;69(6):973-980.

2. Kim M. Intracranial involvement by metastatic advanced gastric carcinoma. J Neurooncol. 1999;43(1):59-62.

3. Kasakura Y, Fujii M, Mochizuki F, Suzuki T, Takahashi T. Clinicopathological study of brain metastasis in gastric cancer patients. Surg Today. 2000;30(6):485-490.

4. Oh SY, Lee SJ, Lee J, et al. Gastric leptomeningeal carcinomatosis: multi-center retrospective analysis of 54 cases. World J Gastroenterol. 2009;15(40):5086-5090.

5. Lee JL, Kang YK, Kim TW et al. Leptomeningeal carcinomatosis in gastric cancer. J Neurooncol. 2004;66(1-2):167-174.

6. Le Rhun E, Taillibert S, Chamberlain MC. Carcinomatous meningitis: Leptomeningeal metastases in solid tumors. Surg Neurol Int. 2013;4(Suppl 4):S265-S288.

7. Van Laer L, Huizing EH, Verstreken M, et al. Nonsyndromic hearing impairment is associated with a mutation in DFNA5. Nat Genet. 1998; 20(2):194-197.

8. Yokomizo K, Harada Y, Kijima K, et al. HYPERLINK "http://www. ncbi.nlm.nih.gov/pubmed/22493364" Methylation of the DFNA5 gene is frequently detected in colorectal cancer. Anticancer Res. 2012;32(4):1319-1322.

9. Fujikane T, Nishikawa N, Toyota M, et al. Genomic screening for genes upregulated by demethylation revealed novel targets of epigenetic silencing in breast cancer. Breast Cancer Res Treat. 2010;122(3):699-710.

10. Akino K, Toyota M, Suzuki H, et al. Identification of DFNA5 as a target of epigenetic inactivation in gastric cancer. Cancer Sci. 2007; 98(1):88-95.

11. Op de Beeck K, Van Camp G, Thys S, et al. The DFNA5 gene, responsible for hearing loss and involved in cancer, encodes a novel apoptosis-inducing protein. Eur J Hum Genet. 2011;19(9):965-973.

12. Kim MS, Lebrom C, Nagpal JK, et al. Methylation of the DFNA5 increases risk of lymph node metastasis in human breast cancer. Biochem and Biophys Res Comm. 2008;370:38-43.

13. Miura M, Iijima N, Hayashida K, et al. Case of leptomeningeal carcinomatosis effectively treated with intrathecal chemotherapy using ventriculoperitoneal shunt. Rinsho Shinkeigaku. 2006;46(6): 404-409.

14. Kim NH, Kim JH, Chin HM, Jun KH. Leptomeningeal carcinomatosis from gastric cancer: single institute retrospective analysis of 9 cases. Ann Surg Treat Res. 2014;86(1):16-21.

15. Masuda M, Kanzaki J. Cause of idiopathic sudden sensorineural hearing loss: The stress response theory. World J Otorhinolaryngol. 2013;3(3):42-57. 
16. Ohno T, Yokoyama Y, Aihara R, et al. Sudden bilateral sensorineural hearing loss as the presenting symptom of meningeal carcinomatosis of gastric cancer: report of a case. Surg Today. 2010;40(6):561-565.

17. Okamoto Y, Sugiyama H, Yamamoto T. A case of meningeal carcinomatosis presenting with bilateral hearing loss. Brain Nerve. 2007;59(12):1385-1389.

18. Schneider S, Krikmann U, Lüüs SM, Kulla A, Haldre S. Neoplastic meningitis as the presenting manifestation of gastric adenocarcinoma. BMJ Case Rep. 2009;2009. pii: bcr07.2008.0565. doi: 10.1136/ bcr.07.2008.0565.
19. Cserni G, Vágó T, Török N, et al. Carcinomatous meningitis. Lege Artis Med. 2007;17(10):688-693.

20. Miura M, Iijima N, Hayashida K, et al. Case of leptomeningeal carcinomatosis effectively treated with intrathecal chemotherapy using ventriculoperitoneal shunt. Rinsho Shinkeigaku. 2006;46(6):404-409.

\section{Publish your work in this journal}

OncoTargets and Therapy is an international, peer-reviewed, open access journal focusing on the pathological basis of all cancers, potential targets for therapy and treatment protocols employed to improve the management of cancer patients. The journal also focuses on the impact of management programs and new therapeutic agents and protocols on

\section{Dovepress}

patient perspectives such as quality of life, adherence and satisfaction. The manuscript management system is completely online and includes a very quick and fair peer-review system, which is all easy to use. Visit http://www.dovepress.com/testimonials.php to read real quotes from published authors.

Submit your manuscript here: http://www.dovepress.com/oncotargets-and-therapy-journal 